\title{
Evaluation of Alexithymia, Anger and Temperament Features in Insomnia Patients with Sexual Dysfunction
}

\author{
Cinsel İşlev Bozukluğu Olan İnsomni Hastalarında Aleksitimi, Öfke ve Mizaç Özelliklerinin \\ Değerlendirilmesi
}

\author{
Esra AYDIN SÜNBÜL ${ }^{1}$ \\ (D) 0000-0003-1864-9345 \\ Pınar ŞEN GÖKÇEIMAAM ${ }^{1}$ \\ (D) 0000-0001-5228-3784 \\ Mehmet Fatih ÜSTÜNDAĞ $\mathbf{1}$ \\ (1) 0000-0003-0897-6000 \\ Nihal TAŞTEKİN ${ }^{2}$ \\ (D) 0000-0001-7737-552X \\ Füsun MAYDA DOMAÇ 3 \\ (1) 0000-0002-5039-7101 \\ Hüseyin GÜLEÇ ${ }^{1}$ \\ (D) 0000-0002-9227-9373
}

\begin{abstract}
Aim: One of the most common sleep disorders is insomnia, and it is also an independent risk factor related to sexual dysfunction (SD). The aim of the present study was to investigate the anger parameters, temperament parameters, and alexithymia in insomnia patients with SD.

Material and Methods: The study group consisted of 92 patients diagnosed with insomnia according to the third edition of the International Classification of Sleep Disorders. The sociodemographic data form, Temperament Evaluation of Memphis, Pisa, Paris and San Diego Auto-questionnaire (TEMPS-A), Insomnia Severity Index (ISI), Toronto Structured Interview for Alexithymia (TSIA), Arizona Sexual Experiences Scale (ASEX), Pittsburgh Sleep Quality Index (PSQI), State-Trait Anger Expression Inventory (STAXI) were applied to the patients. Results: While 62 patients had SD, 30 patients had no SD. ISI, PSQI, anger in score were significantly higher in patients with $\mathrm{SD}(\mathrm{p}=0.048, \mathrm{p}=0.007, \mathrm{p}=0.032$, respectively). While depressive and anxious temperament was significantly higher in patients with $\mathrm{SD}(\mathrm{p}=0.026, \mathrm{p}=0.008$, respectively), hyperthymic temperament was significantly higher in patients without $\mathrm{SD}(\mathrm{p}=0.013)$. ISI score, depressive, and anxious temperament were significantly correlated with the ASEX score $(r=0.214$, $\mathrm{p}=0.041 ; \mathrm{r}=0.261, \mathrm{p}=0.012 ; \mathrm{r}=0.286, \mathrm{p}=0.007$, respectively). Linear regression revealed that depressive, cyclothymic, and irritable temperaments were predictors of ISI ( $\mathrm{p}=0.001)$. According to logistic regression, hyperthymic temperament was an independent predictor of $\mathrm{SD}(\mathrm{p}=0.001)$.

Conclusion: Psychological factors should also be considered in studies conducted on the relationship between insomnia and SD. Further research is needed on temperament characteristics, alexithymia and anger issues. Thus, patients can be approached more comprehensively.
\end{abstract}

Keywords: Sexual dysfunction; insomnia; temperament.

ÖZ

Amaç: İnsomni en yaygın uyku bozukluklarından biridir ve cinsel işlev bozukluğu (CİB) ile ilişkili bağımsız bir risk faktörüdür. Bu çalışmanın amacı CIB olan insomni hastalarında öfke parametrelerini, mizaç parametrelerini ve aleksitimiyi araştırmaktır.

Gereç ve Yöntemler: Çalışmaya uluslararası uyku bozuklukları sınıflandırması üçüncü versiyonuna göre insomni tanıs1 alan 92 hasta dahil edildi. Hastalara sosyodemografik veri formu, Memphis, Pisa, Paris and San Diego mizaç değerlendirme ölçeği (Temperament Evaluation of Memphis, Pisa, Paris, San Diego Auto-questionnaire, TEMPS-A), insomni şiddet ölçeği (Insomnia Severity Index, ISI), Toronto aleksitimi ölçeği (Toronto Structured Interview for Alexithymia, TSIA), Pittsburgh uyku kalitesi ölçeği (Pittsburgh Sleep Quality Index, PSQI), Arizona cinsel yaşantılar ölçeği (Arizona Sexual Experiences Scale, ASEX) ve durumluk-sürekli öfke ifade ölçeği (State-Trait Anger Expression Inventory, STAXI) uygulandı. Bulgular: 62 hastada CIBB varken, 30 hastada CIB yoktu. CIBB olan hastalarda ISI, PSQI ve öfke içeri skoru anlamlı olarak yüksekti (sırasıyla $\mathrm{p}=0,048, \mathrm{p}=0,007, \mathrm{p}=0,032$ ). CIB olan hastalarda depresif ve anksiyöz mizaç anlamlı derecede yüksek iken (sırasıyla $\mathrm{p}=0,026, \mathrm{p}=0,008$ ), hipertimik mizaç CİB olmayan hastalarda anlamlı olarak daha yüksekti $(p=0,013)$. ISI skoru, depresif ve anksiyöz mizaç ile ASEX skoru arasında anlamlı korelasyon saptandı (sırasıyla $r=0,214, p=0,041$; $r=0,261, p=0,012 ; r=0,286, p=0,007)$. Lineer regresyon analizi depresif, siklotimik ve irritabl mizacın ISI'nın ön gördürücüleri olduğunu ortaya koymuştur $(p=0,001)$. Lojistik regresyon analizine göre hipertimik mizaç, CIB' in bağımsız bir ön gördürücüsüdür ( $\mathrm{p}=0,001)$.

Sonuç: İnsomni ve CIB ilişkisine dair yürütülen çalışmalarda psikolojik faktörler de göz önünde bulundurulmalıdır. Mizaç özellikleri, aleksitimi ve öfke konularının daha fazla araştırılması gerekmektedir. Böylece hastalara daha kapsamlı yaklaşılabilir.

Accepted / Kabul Tarihi : 17.08.2021 Available Online /

Çevrimiçi Yayın Tarihi : 20.08.2021

Anahtar kelimeler: Cinsel işlev bozukluğu; insomni; mizaç. 


\section{INTRODUCTION}

One of the most common sleep disorders is insomnia. Many factors such as age, gender, and socioeconomic status are associated with the prevalence of insomnia. It is seen in more than $50 \%$ of people over the age of 65 . It is more common especially in individuals with low socioeconomic status, single or separated, female gender, and during the menopausal period (1). In terms of diagnosis, there should be one of the symptoms such as difficulty in initiating sleep, awaking in the night, waking up early in the morning, and inability to sleep again for at least three months at a frequency of at least three nights a week, and it should cause symptoms that continue throughout the day (2).

In the literature, studies are examining the relationship between insomnia and sexual dysfunction (SD). Sexual desire problems, difficulty in sexual arousal and orgasm, or experiencing rapid orgasm, and sexual pain are the symptoms of SD. The prevalence of low sexual function is about $40-45 \%$ for female and $20-30 \%$ for male (3). It is generally associated with personal and relationship distress, low self-esteem, and decreased quality of life.

Insomnia is an independent risk factor related to SD. Sleep loss can lead to hormonal changes that cause poorer sexual functioning. The effect of insufficient sleep time on sexual function is regulated by low androgen levels. In the literature, the effect of sleep time on sexual desire and the genital response was shown (4).

SD commonly occurs with emotional disorders like depressive and anxiety disorders, although it is independently associated with negative outcomes. It was shown that SD and emotional disorder comorbidity is associated with higher suicidality and increased severity of the disorder (5). Therefore, more studies are needed on the relationship between SD and psychopathology.

Temperament characteristics of patients with SD were investigated in some studies. The level of neuroticism has been found higher in patients with SD. In a study, the NEO-Five Factor Inventory was applied to patients, and frequency of negative sexual cognitions are predicted by neuroticism scores (6). Moreover, SD shares a high level of negative affect that characterizes internalizing disorders, which are a general dimension of sadness, anxiety, anger, and guilt. High levels of these emotions are mostly related to SD, especially to lower sexual arousal and sexual desire in both genders. By following this, patients with SD report higher levels of negative affect, especially during sexual activity. Wiegel et al. (7) reported that $\mathrm{SD}$ is generally associated with temporary or recurrent negative affect.

Alexithymia is defined as the difficulty in identifying feelings, distinguishing between bodily sensations of emotions and feelings. Alexithymia causes dysfunctions in cognitive processing and emotion regulation, so it can lead to lots of psychiatric and medical disorders. Recently, most studies propose the relation between alexithymia and sleep quality. In a previous study, Lindholm et al. (8) demonstrated that alexithymic features were associated with insomnia symptoms such as sleep latency time, and awakenings from sleep. Also, the relation between alexithymia and erectile dysfunction (ED) (9), hypoactive sexual desire (10), and premature ejaculation (11) were shown. The relationship of alexithymia with decreased sexual desire (12), more sexual dissatisfaction (13), and lesser vaginal intercourse frequency (14) were shown in studies with nonclinical female samples.

Anger is another psychological factor that has correlated with SD. The relation of anger with negative penile tumescence and sexual desire was found by Bozman et al. (15) in 1991. They suggested that anger can be one of the mechanisms that prevent desire and arousal in people with hypoactive sexual desire. Incidence of ED is associated with increased expression and suppression of anger.

In this study, we aimed to examine the relations of SD with various psychological factors in insomniac patients. We investigated the temperament characteristics, alexithymia, anger parameters in insomniac patients with SD and compared them with insomniac patients without SD.

\section{MATERIAL AND METHODS}

This study was performed at the Sleep Disorder outpatient clinic of the University Hospital. Following the Helsinki declaration, approval was obtained from the Ethics Committee with decision number 41 on 17.06.2019. The informed consent form was signed by all participants.

\section{Patients}

This observational study consisted of 92 consecutive patients who applied to the Sleep Disorder outpatient clinic of the University Hospital between July 2019 and January 2020 and diagnosed with insomnia according to the third edition of the International Classification of Sleep Disorders (ICSD-3). Inclusion criteria; i. patients without any other accompanying sleep disorder, ii. volunteering to participate in the study and signing the informed consent, iii. being literate, iv. being over the age of 18 . Exclusion criteria; i. having active psychotic symptoms, ii. having active mood disorder, iii. having mental retardation that is understandable by interview, iv. presence of neurocognitive impairment as a result of clinical observation and medical history, v. previous history of any medical or urological diseases that may affect SD.

The sociodemographic data form, Temperament Evaluation of Memphis, Pisa, Paris and San Diego Autoquestionnaire (TEMPS-A), Insomnia Severity Index (ISI), Toronto Structured Interview for Alexithymia (TSIA), Arizona Sexual Experiences Scale (ASEX), Pittsburgh Sleep Quality Index (PSQI), State-Trait Anger Expression Inventory (STAXI) were applied. Cut off score was taken as 11 according to the ASEX, and patients with a score above 11 were considered as SD. Insomnia patients were divided into two groups as "with sexual dysfunction" and "without sexual dysfunction", and anger, alexithymia levels, and temperament characteristics were compared in both of the groups. SD, anger, and alexithymia scores were compared in all insomnia patients, also.

\section{Questionnaires}

Temperament Evaluation of Memphis, Pisa, Paris and San Diego Auto-questionnaire (TEMPS-A) is a selfreport that consists of 35 questions. Questions 1-7 refer to the depressive temperament, 8-14 to the cyclothymic, 1521 to the hyperthymic, 22-28 to the irritable, and 29-35 to the anxious temperament. It is responded in a five-point anchored Likert-type scale ranging from 1 to 5 (1-not all; 2-a little; 3-moderately; 4-much; 5-very much) based on the degree that better describes the way one feels during a 
large part of the life. To evaluate the dominant temperament, the cut points are 13,18, 20,13, and 18 points respectively (16).

Insomnia Severity Index (ISI) is a seven-item questionnaire used to assess sleep quality and insomnia severity (17). The ISI scores range between 0 and 28 . We evaluate the total ISI score.

Pittsburgh Sleep Quality Index (PSQI) measures subjective sleep quality. It consists of 19 self-rated questions and 5 questions rated by the bed partner. It is divided into seven components: subjective sleep quality, sleep latency, sleep duration, sleep efficiency, sleep disturbances, use of sleep medication, and daytime dysfunction. These component scores are added to a total PSQI score with a range of 0 to 21 . While PSQI scores of above 5 are taken as abnormal, higher scores indicate worse sleep quality. The Turkish adaptation of the scale was done by Agargun et al. (18).

Arizona Sexual Experiences Scale (ASEX) is a 5-item scale that measures sexual function in six different levels of answers. The questionnaire enquires about sex drive, erection, arousal, orgasm, and satisfaction. Patients who have ASEX levels above 11 points are regarded as SD.

Toronto Structured Interview for Alexithymia (TSIA) is a 20-item self-report scale. Items are rated on a 1-5 scale. Higher total scores indicate greater levels of alexithymia. It has also three subscales measuring difficulty in identifying feelings and distinguishing them from bodily sensations of emotion, difficulty expressing feelings, and externally oriented thinking. The Turkish translation of the TAS-20 has good reliability $(\alpha=0.76,19)$.

State-Trait Anger Expression Inventory (STAXI) is a self-report inventory which is consisting of 44 items coded on a 4-point scale. State anger, trait anger, anger in, anger out, anger control, and anger expression are subscales. The first 10 items in the scale are the items of the Trait Anger subscale. With the addition of items 13, 15, 16, 20, 23, 26, 27, and 31, the score of the anger in sub-scale of the Anger Style scale; Anger Outward subscale score, with the addition of items 12,17, 19, 22, 24, 29, 32 and 33; the scores of the Anger Control subscale are obtained by summing the items no $11,14,18,21,25,28,30$ and 34 . High scores from Trait Anger indicate that the level of anger is high; high scores on the Control Anger scale indicated that anger can be controlled; high scores on the Anger-Out Scale indicate that anger is easily expressed.

\section{Statistical Analysis}

Statistical analysis was performed using the SPSS for Windows (version 20.0; SPSS Inc, Chicago, Illinois). The Shapiro-Wilk test was used to determine whether the data were normally distributed. Continuous data were expressed as mean \pm standard deviation or median (interquartile range) while categorical data were presented as the number of patients and percentages. Student's t-test or Mann-Whitney-U test was used to compare parametric and non-parametric continuous variables, respectively. Pearson chi-square and Fisher's exact tests were used for statistical evaluation of the categorical variables. Correlation analysis was performed by Pearson or Spearman's correlation test. Linear regression analysis was performed to demonstrate the predictors of the ISI score. Parameters included depressive temperament, cyclothymic temperament, hyperthymic temperament, irritable temperament, anxious temperament, alexithymia, and ASEX based on the univariate analysis findings. Logistic regression analysis was performed to demonstrate the predictors of SD. Parameters included age, gender, ISI score, total PSQI score, anxious temperament, and depressive temperament based on the univariate analysis findings. Hosmer-Lemeshow goodness-of-fit statistic was used to assess model fit. A p-value $<0.05$ was considered statistically significant.

\section{RESULTS}

The mean age of patients was $54.9 \pm 8.7$ years. Most of the patients $(73.9 \%, n=68)$ were female. $19(20.7 \%)$ of the patients had a cigarette and $20(21.7 \%)$ had alcohol use. While the mean duration of the insomnia complaints of the patients was $11.7 \pm 6.4$ years, the mean duration of the insomnia diagnosis was $3.3 \pm 2.8$ years. The mean ISI score of the patients was $19.8 \pm 4.8$. The mean total PSQI score of the patients was $16.8 \pm 3.7$ (Table 1 ).

The cut-off score was taken as 11 according to the ASEX, and patients with a score above 11 are considered SD. Insomnia patients are divided into two groups as "patients with SD" and "patients without SD". While 62 patients had SD, 30 patients had no SD. The mean ASEX score of the patients with SD was $20.9 \pm 5.7$. There was no significant difference between the groups in terms of age $(\mathrm{p}=0.187)$. While $52(83.9 \%)$ of the patients with SD were female, there were $16(53.3 \%)$ females in the group without SD. There was a significant difference between the groups in terms of gender $(p=0.002)$. There was no significant difference between the groups in terms of marital status, employment status, smoking, and alcohol use $(p=0.293$, $\mathrm{p}=0.095, \mathrm{p}=0.281, \mathrm{p}=0.778$, respectively). Duration of insomnia and diagnosis time were significantly higher in patients with $\mathrm{SD}(\mathrm{p}=0.021$, and $\mathrm{p}=0.003$ respectively). ISI and PSQI scores were significantly higher in patients with $\mathrm{SD}(\mathrm{p}=0.048$, and $\mathrm{p}=0.007$, respectively, Table 2 ).

Anger scores, TEMPS-A parameters, and alexithymia were compared between patients with and without SD in Table 3. When the anger scores were compared between the groups; anger in score was significantly higher in patients with $\mathrm{SD}(\mathrm{p}=0.032)$. Trait anger and anger out scores were significantly higher in patients without SD ( $\mathrm{p}=0.028$, and $\mathrm{p}=0.029$, respectively). Anger control scores was not different between groups $(\mathrm{p}=0.676)$. According to the examination of temperament characteristics, depressive and anxious temperament were

Table 1. Baseline characteristics and clinical data of the patients $(n=92)$

\begin{tabular}{lc}
\hline Age (years), mean \pm SD & $54.9 \pm 8.7$ \\
Sex (female), n (\%) & $68(73.9)$ \\
Smoking, n (\%) & $19(20.7)$ \\
Alcohol, n (\%) & $20(21.7)$ \\
Married, n (\%) & $62(67.4)$ \\
Working, n (\%) & $21(22.8)$ \\
Onset of symptoms (years), mean \pm SD & $11.7 \pm 6.4$ \\
Diagnosis of insomnia (years), mean \pm SD & $3.3 \pm 2.8$ \\
Insomnia Severity Index, mean \pm SD & $19.8 \pm 4.8$ \\
Total Pittsburgh Sleep Quality Index, mean \pm SD & $16.8 \pm 3.7$ \\
\hline SD: standard deviation &
\end{tabular}


Table 2. Comparison of baseline characteristics and clinical data between groups

\begin{tabular}{lccc}
\hline & $\begin{array}{c}\text { Patients without sexual } \\
\text { dysfunction (n=30) }\end{array}$ & $\begin{array}{c}\text { Patients with sexual } \\
\text { dysfunction (n=62) }\end{array}$ & p \\
\hline Age (years), mean \pm SD & $53.1 \pm 7.5$ & $55.7 \pm 9.2$ & 0.187 \\
Gender (female), n (\%) & $16(53.3)$ & $52(83.9)$ & $\mathbf{0 . 0 0 2}$ \\
Married, n (\%) & $18(60.0)$ & $44(71.0)$ & 0.293 \\
Working, n (\%) & $10(33.3)$ & $11(17.7)$ & 0.095 \\
Smoking, n (\%) & $4(13.3)$ & $15(24.2)$ & 0.281 \\
Alcohol, n (\%) & $6(20.0)$ & $14(22.6)$ & 0.778 \\
Onset of symptoms (years), median (IQR) [min-max] & $8(11)[2-20]$ & $10(13)[3-37]$ & $\mathbf{0 . 0 2 1}$ \\
Diagnosis of insomnia (years), median (IQR) [min-max] & $1(3.25)[1-10]$ & $3(2)[1-15]$ & $\mathbf{0 . 0 0 3}$ \\
Insomnia Severity Index, median (IQR) [min-max] & $19(8)[8-26]$ & $19(6)[12-28]$ & $\mathbf{0 . 0 4 8}$ \\
Pittsburgh Sleep Quality Index, median (IQR) [min-max] & $17(7)[10-20]$ & $19(4)[6-21]$ & $\mathbf{0 . 0 0 7}$ \\
\hline SD: standard deviation, IQR: interquartile range & & &
\end{tabular}

Table 3. Comparison of Anger scores, TEMPS-A parameters, and alexithymia between groups

\begin{tabular}{lccc}
\hline Median (IQR) [min-max] & $\begin{array}{c}\text { Patients without sexual } \\
\text { dysfunction (n=30) }\end{array}$ & $\begin{array}{c}\text { Patients with sexual } \\
\text { dysfunction }(\mathbf{n = 6 2})\end{array}$ & $\mathbf{p}$ \\
\hline Trait anger & $22(8)[16-29]$ & $19.5(6.25)[13-37]$ & $\mathbf{0 . 0 2 8}$ \\
Anger in & $15(8.5)[10-25]$ & $21(10)[10-29]$ & $\mathbf{0 . 0 3 2}$ \\
Anger out & $16(6)[13-22]$ & $14.5(8)[9-27]$ & $\mathbf{0 . 0 2 9}$ \\
Anger control & $18(10.5)[11-30]$ & $21(6)[13-31]$ & 0.676 \\
Depressive temperament & $7(4.25)[2-15]$ & $8.5(8)[1-16]$ & $\mathbf{0 . 0 2 6}$ \\
Cyclothymic temperament & $9(7.25)[1-18]$ & $8(11)[1-17]$ & 0.547 \\
Hyperthymic temperament & $8(9.25)[0-17]$ & $8(6)[0-16]$ & $\mathbf{0 . 0 1 3}$ \\
Irritable temperament & $7(7.25)[0-12]$ & $3(5.25)[0-14]$ & 0.164 \\
Anxious temperament & $4(9)[0-21]$ & $12(12)[0-21]$ & $\mathbf{0 . 0 0 8}$ \\
Alexithymia & $62(22.75)[41-74]$ & $52(19)[28-84]$ & 0.223 \\
\hline TEMPS-A Temperament Evaluation of Memphis. Pisa, Paris, San Diego Auto-questionnaire, IQR: interquartile range & &
\end{tabular}

TEMPS-A: Temperament Evaluation of Memphis, Pisa, Paris, San Diego Auto-questionnaire, IQR: interquartile range

Table 4. Correlation analysis between ASEX score, ISI score and TEMPS-A parameters

\begin{tabular}{|c|c|c|c|c|c|c|c|}
\hline & ASEX & ISI & Depressive $\mathbf{T}$ & Anxious T & Cyclothymic $\mathbf{T}$ & Hyperthymic T & Irritable $\mathbf{T}$ \\
\hline \multirow{2}{*}{ ASEX } & & $\mathrm{r}=0.214$ & $\mathrm{r}=0.261$ & $\mathrm{r}=0.286$ & $\mathrm{r}=0.091$ & $\mathrm{r}=-0.189$ & $\mathrm{r}=-0.168$ \\
\hline & - & $p=0.041$ & $\mathrm{p}=\mathbf{0 . 0 1 2}$ & $\mathrm{p}=\mathbf{0 . 0 0 7}$ & $\mathrm{p}=0.390$ & $\mathrm{p}=0.071$ & $\mathrm{p}=0.110$ \\
\hline \multirow{2}{*}{ ISI } & $\mathrm{r}=0.214$ & & $\mathrm{r}=0.113$ & $\mathrm{r}=0.162$ & $\mathrm{r}=0.336$ & $\mathrm{r}=0.007$ & $\mathrm{r}=0.032$ \\
\hline & $p=0.041$ & - & $\mathrm{p}=0.282$ & $\mathrm{p}=0.132$ & $p=0.001$ & $\mathrm{p}=0.944$ & $\mathrm{p}=0.765$ \\
\hline \multirow{2}{*}{ Depressive T } & $\mathrm{r}=0.261$ & $\mathrm{r}=0.113$ & & $\mathrm{r}=0.630$ & $\mathrm{r}=0.629$ & $\mathrm{r}=0.068$ & $\mathrm{r}=0.528$ \\
\hline & $\mathrm{p}=\mathbf{0 . 0 1 2}$ & $\mathrm{p}=0.282$ & $\begin{array}{l}- \\
-\end{array}$ & $\mathrm{p}<\boldsymbol{0 . 0 0 1}$ & $\mathrm{p}<\mathbf{0 . 0 0 1}$ & $\mathrm{p}=0.522$ & $\mathrm{p}<\mathbf{0 . 0 0 1}$ \\
\hline \multirow{2}{*}{ Anxious T } & $\mathrm{r}=0.286$ & $r=0.162$ & $\mathrm{r}=0.630$ & & $\mathrm{r}=0.735$ & $r=0.169$ & $r=0.644$ \\
\hline & $\mathrm{p}=\mathbf{0 . 0 0 7}$ & $\mathrm{p}=0.132$ & $\mathrm{p}<\mathbf{0 . 0 0 1}$ & - & $\mathrm{p}<0.001$ & $\mathrm{p}=0.115$ & $\mathrm{p}<0.001$ \\
\hline \multirow{2}{*}{ Cyclothymic T } & $\mathrm{r}=0.091$ & $r=0.336$ & $r=0.629$ & $\mathrm{r}=0.735$ & & $\mathrm{r}=0.247$ & $\mathrm{r}=0.767$ \\
\hline & $\mathrm{p}=0.390$ & $p=0.001$ & $\mathrm{p}<\mathbf{0 . 0 0 1}$ & $\mathrm{p}<0.001$ & $\begin{array}{lll}- & - \\
-1\end{array}$ & $\mathrm{p}=\mathbf{0 . 0 1 8}$ & $\mathrm{p}<\mathbf{0 . 0 0 1}$ \\
\hline \multirow{2}{*}{ Hyperthymic T } & $\mathrm{r}=-0.189$ & $\mathrm{r}=0.007$ & $\mathrm{r}=0.068$ & $\mathrm{r}=0.169$ & $\mathrm{r}=0.247$ & & $\mathrm{r}=0.443$ \\
\hline & $\mathrm{p}=0.071$ & $\mathrm{p}=0.944$ & $\mathrm{p}=0.522$ & $\mathrm{p}=0.115$ & $\mathrm{p}=\mathbf{0 . 0 1 8}$ & - & $\mathrm{p}<\mathbf{0 . 0 0 1}$ \\
\hline \multirow{2}{*}{ Irritable T } & $r=-0.168$ & $\mathrm{r}=0.032$ & $\mathrm{r}=0.528$ & $r=0.644$ & $r=0.767$ & $\mathrm{r}=0.443$ & \\
\hline & $\mathrm{p}=0.110$ & $\mathrm{p}=0.765$ & $\mathrm{p}<\mathbf{0 . 0 0 1}$ & $\mathrm{p}<0.001$ & $\mathrm{p}<\mathbf{0 . 0 0 1}$ & $\mathrm{p}<\mathbf{0 . 0 0 1}$ & - \\
\hline
\end{tabular}

significantly higher in patients with $\mathrm{SD}(\mathrm{p}=0.026$, and $\mathrm{p}=0.008$, respectively), whereas hyperthymic temperament was significantly higher in patients without $\mathrm{SD}(\mathrm{p}=0.013)$. Alexithymia score was not significantly different between groups $(\mathrm{p}=0.223)$.

Correlation analysis was performed to demonstrate the association between ASEX score with ISI and TEMPS-A parameters (Table 4). ASEX score was significantly correlated with the ISI score $(\mathrm{r}=0.214, \mathrm{p}=0.041)$. Among TEMPS-A parameters; depressive and anxious temperament was significantly correlated with ASEX score $(\mathrm{r}=0.261, \mathrm{p}=0.012 ; \mathrm{r}=0.286, \mathrm{p}=0.007$, respectively). Multivariate linear regression analysis was performed to demonstrate the predictors of ISI. Among TEMPS-A parameters, alexithymia, and ASEX score; depressive temperament, cyclothymic temperament, and irritable temperament were predictors of ISI ( $\mathrm{p}=0.001$, Table 5). Multivariate logistic regression analysis was performed to demonstrate the predictors of SD. Among age, gender, ISI score, PSQI score, anxious, depressive, and hyperthymic temperaments; hyperthymic temperament was independent predictor of SD ( $\mathrm{p}=0.001$, Table 6). 
Table 5. Multivariate linear regression analysis to determinate predictors of ISI

\begin{tabular}{lccccc}
\hline & B & Beta & t & $\mathbf{9 5 \%}$ CI & p \\
\hline Depressive T & -0.294 & -0.327 & -2.500 & $-0.529--0.060$ & $\mathbf{0 . 0 1 4}$ \\
Cyclothymic T & 0.514 & 0.641 & 3.580 & $0.228-0.800$ & $\mathbf{0 . 0 0 1}$ \\
Hyperthymic T & 0.046 & 0.055 & 0.499 & $-0.138-0.230$ & 0.619 \\
Irritable T & -0.358 & -0.355 & -2.000 & $-0.713--0.002$ & $\mathbf{0 . 0 4 9}$ \\
Anxious T & -0.003 & 0.103 & -0.031 & $-0.209-0.203$ & 0.975 \\
Alexithymia & 0.052 & 0.165 & 1.555 & $-0.015-0.119$ & 0.124 \\
ASEX & 0.085 & 0.153 & 1.278 & $-0.047-0.216$ & 0.205 \\
\hline
\end{tabular}

ISI: insomnia severity index, CI: confidence interval, T: Temperament, ASEX: Arizona Sexual Experiences Scale

Table 6. Multivariate logistic regression analysis to determinate predictors of SD

\begin{tabular}{lccc}
\hline & OR & $\mathbf{9 5 \%}$ CI & p \\
\hline Age & 1.023 & $0.955-1.097$ & 0.511 \\
Gender & 2.423 & $0.680-8.631$ & 0.172 \\
ISI score & 1.011 & $0.882-1.159$ & 0.872 \\
Total PSQI score & 1.175 & $0.988-1.398$ & 0.069 \\
Anxious temperament & 1.078 & $0.952-1.222$ & 0.236 \\
Depressive temperament & 1.032 & $0.875-1.218$ & 0.707 \\
Hyperthymic temperament & 0.857 & $0.770-0.954$ & $\mathbf{0 . 0 0 5}$ \\
\hline
\end{tabular}

SD: sexual dysfunction, OR: odds ratio, CI: confidence interval, ISI: insomnia severity index, PSQI: Pittsburgh Sleep Quality Index

\section{DISCUSSION}

Because of the different diagnostic and screening methods, the prevalence of insomnia varies from $6-76.3 \%$. The environmental factors affect the prevalence of insomnia. Sociodemographic factors such as sex, age, marital status, income, education, occupation, and somatic or psychiatric conditions are associated with insomnia.

Sex differences are widely mentioned in the sleep literature. In a study, it was shown that insomnia in females is 1.5 times higher than in males (20). Similarly, we found that insomnia was more common in females $(n=68,73,9 \%)$. Because females are more likely to mention their somatic symptoms (21). In previous studies, it was shown that females with insomnia attend to hospital more than males $(22,23)$.

Benbir et al. (24) searched the prevalence of insomnia in Turkey. They observed that the prevalence of insomnia is $12.2 \%$ while the prevalence of any symptom of insomnia is $51 \%$. In their study, of the 5021 participants, $51.7 \%$ were female, $14.8 \%$ were aged $18-24$ years, $47.6 \%$ were aged $25-44$ years, $29.3 \%$ were aged $45-64$ years, and $8.3 \%$ were older than 64 years. In another study, individuals in the 55 to 64-year age group had a higher rate of insomnia (25). Therefore, the prevalence of insomnia increases with age, and then peaks in the 45-64 years of age. Similarly, participants with $54.9 \pm 8.7$ years mostly reported insomnia in our study. Stressors related to retirement, taking care of parents, supporting children, and increase risk of medical illness may be the reasons for insomnia in this age group (26).

Previous studies in Western countries mentioned that divorced, separated, and widowed subjects had a higher prevalence of insomnia (27). Similarly, Benbir et al. (24) also observed that insomnia was more in divorced people. On the contrary, in our study $62(67.4 \%)$ patient was married. This can be explained by stressful life events caused by marriage, problems with the children, and other family members.

In a study, it was shown that insomnia was higher in unemployed people and housewives than people with a regular salary (24). Similar to this data only 21 (22.8\%) patients were working in our study. Although smoking and drinking are risk factors for insomnia in some studies $(28,29)$, there were contemporary results also (25). In our study, only $19(20.7 \%)$ patients were smoking and $20(21.7 \%)$ patients had alcohol consumption. The impact of smoking and drinking on insomnia needs to be further explored.

The relation between sleep, the endocrine system, and sexual functions are not yet clearly understood. Studies on the prevalence and characteristics of SD in patients reporting symptoms of sleep disorders are scarce and limited to specific research groups. Most data refer to the $\mathrm{SD}$ in the population of male with obstructive sleep apnea syndrome and the SD in the perimenopausal female with comorbid insomnias (30). They suggest that insufficient sleep duration and sleep quality affect sexual responses negatively. Kalmbach et al. (31) demonstrated that higher sleep duration was associated with higher sexual desire. In our study, $62(67.4 \%)$ of the 92 insomnia patients included in the study had SD; ISI and PSQI scores were significantly higher in this group.

Previous studies reported a broad range of prevalence rates due to different age groups, dysfunction description, data selection and collection, duration of dysfunction, and the severity of the dysfunction. Therefore, epidemiological studies indicate that nearly $20-30 \%$ of adult males and $40-45 \%$ of adult females have at least one SD. As the age increases, the prevalence of SD also increases. Although some studies show that SD increases especially after the age of 50, some studies have not shown its relevance to age (32). In our study, when patients with and without SD were compared, there was no significant difference in age. But, the rate of women in the group with SD was significantly higher. Vulvovaginal atrophy and hypoactive sexual desire disorder can be seen due to hormonal changes during menopause. This situation may cause impairment in the sexual functions of women in this age group.

In the literature, it was shown that females with vaginismus were at a higher risk of depressive, cyclothymic, anxious, and irritable temperament than controls, although there were no significant differences in the hyperthymic temperament scores between groups (33). Similarly, in our study, the group with SD had significantly higher scores of depressive and anxious temperaments; however, hyperthymic scores were significantly higher in the group without SD. Depressive and anxious temperament may be considered to have negative effects on sexual functions, both by causing the development of depressive and anxious symptoms leading to anhedonia, lack of energy, and decrease in desire. Previous studies defined hyperthymic temperament as extraversion (34). They found hyperthymic temperament was protective against any anxiety disorder and mood disorder (35). Perhaps this is why hyperthymic temperament was higher in the group without SD.

Anger is an emotional conflict that can interrupt SD. The role of anger in SD was investigated in previous studies. Anger in reactions and anger-related behaviors scores were found significantly higher in patients with SD than 
without SD (36). On the contrary, in 2000, the Massachusetts Male Aging Study (37) showed that anger in and anger out do not predict the presence of ED. Muscatello et al. (38) showed that trait anger was not related to sexual motivation; but trait anger was related to sexual interpersonal behavior, especially in males. In another study, Iannuzzo et al. (39) demonstrated that anger-prone individuals aim to meet their own needs and desires, but not their partner's. So, they are interested in sexual pleasure. In our study anger in score was significantly higher in patients with SD. This can be explained by anger can tense the body, so it prevents the relaxation that has a negative impact on sexual pleasure. Or, anger can be experienced as problematic and dangerous that results in anxiety and confusion and leads to SD.

In previous studies, it was shown that greater alexithymia was associated with ED, hypoactive sexual desire, and premature ejaculation (11). Studies with female samples show associations of alexithymia with SD. Berunger et al. (40) showed the correlation of greater alexithymia with more erectile difficulties, while not with difficulties delaying ejaculation during vaginal intercourse in nonclinical sample. In our study alexithymia score was not significantly different between groups. Therefore, further researches are needed to investigate if alexithymia is more related to some SD.

Our study had several limitations. Firstly, the study sample size was small. This may affect the power of the correlation analysis. Secondly, our study was crosssectional and comes with some limitations. The crosssectional nature of the study does not allow one to draw strong conclusions about the clinical utility of the proposed questionnaires. Our study population did not cover the younger age population. Further prospective studies are needed to demonstrate the effect of age on the study results.

\section{CONCLUSION}

In conclusion, psychological factors should also be considered in studies conducted on the relationship between insomnia and SD. The results of the current study showed that ISI score, depressive and anxious temperament was significantly correlated with ASEX score. Depressive, cyclothymic, and irritable temperament were predictors of ISI. Hyperthymic temperament was predictor of SD. Further research is needed on temperament characteristics, alexithymia and anger issues. Thus, patients can be approached more comprehensively.

Ethics Committee Approval: The study was approved by the Clinical Research Ethics Committee of University of Health Sciences Erenköy Mental and Neurological Diseases Training and Research Hospital (17.06.2019, 41).

Conflict of Interest: None declared by the authors.

Financial Disclosure: None declared by the authors.

Acknowledgements: None declared by the authors.

Author Contributions: Idea/Concept: EAS; Design: MFÜ; Data Collection/Processing: NT; Analysis/Interpretation: HG; Literature Review: PŞG; Drafting/Writing: EAS; Critical Review: FMD.

\section{REFERENCES}

1. Ohayon MM. Epidemiology of insomnia: what we know and what we still need to learn. Sleep Med Rev. 2002;6(2):97-111.

2. American Academy of Sleep Medicine. International Classification of Sleep Disorders. 3rd ed. Darien, IL: American Academy of Sleep Medicine; 2014.

3. Lewis RW, Fugl-Meyer KS, Corona G, Hayes RD, Laumann EO, Moreira ED Jr, et al. Definitions/epidemiology/risk factors for sexual dysfunction. J Sex Med. 2010;7(4 Pt 2):1598-607.

4. Kalmbach DA, Arnedt JT, Pillai V, Ciesla JA. The impact of sleep on female sexual response and behavior: a pilot study. J Sex Med. 2015;12(5):122132.

5. Rajkumar RP, Kumaran AK. Depression and anxiety in men with sexual dysfunction: a retrospective study. Compr Psychiatry. 2015;60:114-8.

6. Moyano N, Sierra JC. Relationships between personality traits and positive/negative sexual cognitions. Int J Clin Health Psychol. 2013;13(3):18996.

7. Wiegel M, Scepkowski LA, Barlow DH. Cognitiveaffective processes in sexual arousal and sexual dysfunction. In: Janssen E, editor. The psychophysiology of sex. Bloomington: Indiana University Press; 2007. p.143-65.

8. Lindholm T, Lehtinen V, Hyyppä MT, Puukka P. Alexithymic features in relation to the dexamethasone suppression test in a Finnish population sample. Am J Psychiatry. 1990;147(9):1216-9.

9. Michetti PM, Rossi R, Bonanno D, Tiesi A, Simonelli C. Male sexuality and regulation of emotions: a study on the association between alexithymia and erectile dysfunction (ED). Int J Impot Res. 2006;18(2):170-4.

10. Madioni F, Mammana LA. Toronto Alexithymia Scale in outpatients with sexual disorders. Psychopathology. 2001;34(2):95-8.

11. Michetti PM, Rossi R, Bonanno D, De Dominicis C, Iori F, Simonelli C. Dysregulation of emotions and premature ejaculation (PE): alexithymia in 100 outpatients. J Sex Med. 2007;4(5):1462-7.

12. Costa RM, Oliveira G, Pestana J, Costa D, Oliveira RF. Do psychosocial factors moderate the relation between testosterone and female sexual desire? The role of interoception, alexithymia, defense mechanisms, and relationship status. Adapt Hum Behav Physiol. 2019;5(1):13-30.

13. Scimeca G, Bruno A, Pandolfo G, Micò U, Romeo VM, Abenavoli E, et al. Alexithymia, negative emotions, and sexual behavior in heterosexual university students from Italy. Arch Sex Behav. 2013;42(1):117-27.

14. Brody S, Laan E, van Lunsen RH. Concordance between women's physiological and subjective sexual arousal is associated with consistency of orgasm during intercourse but not other sexual behavior. J Sex Marital Ther. 2003;29(1):15-23.

15. Bozman AW, Beck JG. Covariation of sexual desire and sexual arousal: the effects of anger and anxiety. Arch Sex Behav. 1991;20(1):47-60.

16. Pompili M, Girardi P, Tatarelli R, Iliceto P, De Pisa E, Tondo L, et al. TEMPS-A (Rome): Psychometric 
validation of affective temperaments in clinically well subjects in mid- and south Italy. J Affect Disord. 2008;107(1-3):63-75.

17. Bastien CH, Vallieres A, Morin CM. Validation of the Insomnia Severity Index as an outcome measure for insomnia research. Sleep Med. 2001;2(4):297-307.

18. Yücel Ağargün M, Kara H, Anlar Ö. The validity and reliability of the Pittsburgh Sleep Quality Index. Turk Psikiyatri Derg. 1996;7(2):107-15.

19. Sayar K, Güleç H, Ak I. [Reliability and validity study of Toronto alexithymia scale]. İstanbul: $37^{\text {th }}$ National Congress of Psychiatry, Scientific Studies Abstract Book; 2001. p.130. Turkish.

20. Zhang B, Wing YK. Sex differences in insomnia: a meta-analysis. Sleep 2006;29(1):85-93.

21. Barsky AJ, Peekna HM, Borus JF. Somatic symptom reporting in women and men. J Gen Intern Med. 2001;16(4):266-75.

22. Liu Y, Zhang J, Lam SP, Yu MW, Li SX, Zhou J, et al. Help seeking behaviors for insomnia in Hong Kong Chinese: a community-based study. Sleep Med. 2016;21:106-13.

23. Morin CM, LeBlanc M, Daley M, Gregoire JP, Mérette C. Epidemiology of insomnia: prevalence, self-help treatments, consultations, and determinants of helpseeking behaviors. Sleep Med. 2006;7(2):123-30.

24. Benbir G, Demir AU, Aksu M, Ardic S, Firat H, Itil O, et al. Prevalence of insomnia and its clinical correlates in a general population in Turkey. Psychiatry Clin Neurosci. 2015;69(9):543-52.

25. Xiang YT, Ma X, Cai ZJ, Li SR, Xiang YQ, Guo HL, et al. The prevalence of insomnia, its sociodemographic and clinical correlates, and treatment in rural and urban regions of Beijing, China: a general population-based survey. Sleep. 2008;31(12):1655-62.

26. He J, Luan QM, Xie CG, Du CY, Cheng YR. Quality of life and mental state of those retired. Chin Ment Health J. 2002;16(3):177-8. Chinese.

27. Allaert FA, Urbinelli R. Sociodemographic profile of insomniac patients across national surveys. CNS Drugs. 2004;18(Suppl 1):3-7; discussion 41,43-5.

28. Kaneita Y, Ohida T, Osaki Y, Tanihata T, Minowa M, Suzuki K, et al. Insomnia among Japanese adolescents: a nationwide representative survey. Sleep. 2006;29(12):1543-50.

29. Jefferson CD, Drake CL, Scofield HM, Myers E, McClure T, Roehrs T, et al. Sleep hygiene practices in a population-based sample of insomniacs. Sleep. 2005;28(5):611-5.

30. İrer B, Çelikhisar A, Çelikhisar H, Bozkurt O, Demir Ö. Evaluation of sexual dysfunction, lower urinary tract symptoms and quality of life in men with obstructive sleep apnea syndrome and the efficacy of continuous positive airway pressure therapy. Urology. 2018;121:86-92.

31. Kalmbach DA, Arnedt JT, Pillai V, Ciesla JA. The impact of sleep on female sexual response and behavior: a pilot study. J Sex Med. 2015;12(5):122132.

32. Lewis RW, Fugl-Meyer KS, Bosch R, Fugl-Meyer AR, Laumann EO, Lizza E, et al. Definitions, classification, and epidemiology of sexual dysfunction. In: Lue TF, Basson R, Rosen R, Giuliano F, Khoury S, Montorsi F, editors. Sexual medicine: sexual dysfunction in men and women. United Kingdom: Health Publications; 2004. p.1-36.

33. Turan Ş, Usta Sağlam NG, Bakay H, Gökler ME. Levels of depression and anxiety, sexual functions, and affective temperaments in women with lifelong vaginismus and their male partners. J Sex Med. 2020;17(12):2434-45.

34. Rózsa S, Rihmer Z, Gonda X, Szili I, Rihmer A, Ko N, et al. A study of affective temperaments in Hungary: internal consistency and concurrent validity of the TEMPS-A against the TCI and NEO-PI-R. J Affect Disord. 2008;106(1-2):45-53.

35. Karam EG, Salamoun MM, Yeretzian JS, Mneimneh ZN, Karam AN, Fayyad J, et al. The role of anxious and hyperthymic temperaments in mental disorders: a national epidemiologic study. World Psychiatry. 2010;9(2):103-10.

36. Hisli Şahin N, Durak Batıün A, Alkan Pazvantoğlu E. [The role of interpersonal style, self perception and anger in sexual dysfunction]. Turk Psikiyatri Derg. 2012;23(1):18-25. Turkish.

37. Araujo AB, Johannes CB, Feldman HA, Derby CA, McKinlay JB. Relation between psychosocial risk factors and incident erectile dysfunction: prospective results from the Massachusetts Male Aging Study. Am J Epidemiol. 2000;152(6):533-41.

38. Muscatello MR, Bruno A, Scimeca G, Pandolfo G, Paduano R, Mico U, et al. The relationship between anger and heterosexual behavior. An investigation in a nonclinical sample of urban Italian undergraduates. J Sex Med. 2010;7(12):3899-908.

39. Iannuzzo G, Pandolfo G, Bonadonna A, Lorusso S, Crucitti M, Lanza G, et al. The relationship between anger and sexual behavior: a review of theories and research. Mediterr J Clin Psychol. 2014;2(1):1-29.

40. Berenguer C, Rebôlo C, Costa RM. Interoceptive awareness, alexithymia, and sexual function. J Sex Marital Ther. 2019;45(8):729-38. 